\title{
Serotype distribution of invasive, non- invasive and carried Streptococcus pneumoniae in Malaysia: a meta-analysis
}

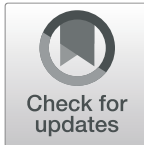

Alex J. J. Lister ${ }^{1}$, Cheng Foh Le², Eddy Seong Guan Cheah³ ${ }^{3}$, Mohd Nasir Mohd Desa ${ }^{4}$, David W. Cleary ${ }^{1,5}$ and Stuart C. Clarke $e^{1,5,6,7^{*}}$

\begin{abstract}
Background: Pneumococcal pneumonia is the leading cause of under-five mortality globally. The surveillance of pneumococcal serotypes is therefore vital for informing pneumococcal vaccination policy and programmes. Pneumococcal conjugate vaccines (PCVs) have been available as an option in the private healthcare setting and beginning December 2020, PCV10 was incorporated as part of routine national immunisation programme (NIP) in Malaysia. We searched existing literature on pneumococcal serotype distribution across Malaysia to provide an overall view of this distribution before the implementation of PCV10.

Methods: Online databases (PubMed, Ovid MEDLINE and Scopus), reference lists of articles identified, and grey literature (Malaysian Ministry of Health website, WHO website) were systematically searched for relevant literature on pneumococcal serotype distribution across Malaysia up to 10th November 2020. No lower date limit was set to maximise the number of target reports returned. Results of serotypes were split by age categories, including $\leq 5$ years, $>5$ years and unreported for those that did not specify.

Results: The search returned 18 relevant results, with a total of 2040 isolates. The most common serotypes across all disease types were 19F ( $n=313,15.3 \%$ [95\%Cl: 13.8-17.0]), 23F ( $n=166,8.1 \%$ [95\%Cl: 7.0-9.4]), 14 ( $n=166,8.1 \%$ [95\%Cl: 7.0-9.4]), 6B ( $n=163,8.0 \%$ [95\%Cl: 6.9-9.2]) and 19A ( $n=138,6.8 \%$ [95\%Cl: 5.8-7.9]).

Conclusion: Four of the most common serotypes across all isolate sources in Malaysia are covered by PCV10, while PCV13 provides greater serotype coverage in comparison to PCV10. There is still a need for surveillance studies, particularly those investigating serotypes in children under 5 years of age, to monitor vaccine effectiveness and pneumococcal population dynamic following implementation of PCV10 into routine immunisation.
\end{abstract}

Keywords: Pneumococcal disease, National Immunisation Programme, Vaccine types, PCV10, PCV13, Pneumonia, Vaccine, Serotype, Antimicrobial resistance

\footnotetext{
* Correspondence: s.c.clarke@soton.ac.uk

${ }^{1}$ Faculty of Medicine and Institute for Life Sciences, Infectious Disease

Epidemiology Group, University of Southampton, Mailpoint 814, Level C, Sir

Henry Wellcome Laboratories, South Block, University Hospital Southampton

Foundation NHS Trust, Southampton SO16 6YD, UK

${ }^{5} \mathrm{NIHR}$ Southampton Biomedical Research Centre, University Hospital

Southampton Foundation NHS Trust, Southampton, UK

Full list of author information is available at the end of the article
}

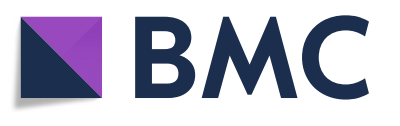

() The Author(s). 2021 Open Access This article is licensed under a Creative Commons Attribution 4.0 International License, which permits use, sharing, adaptation, distribution and reproduction in any medium or format, as long as you give appropriate credit to the original author(s) and the source, provide a link to the Creative Commons licence, and indicate if changes were made. The images or other third party material in this article are included in the article's Creative Commons licence, unless indicated otherwise in a credit line to the material. If material is not included in the article's Creative Commons licence and your intended use is not permitted by statutory regulation or exceeds the permitted use, you will need to obtain permission directly from the copyright holder. To view a copy of this licence, visit http://creativecommons.org/licenses/by/4.0/. 


\section{Introduction}

Streptococcus pneumoniae infection remains the leading cause of bacterial pneumonia worldwide but can also lead to other life-threatening invasive pneumococcal diseases (IPDs) such as meningitis and sepsis, as well as non-invasive diseases (non-IPDs) such as sinusitis and otitis media [1]. The causative bacterium typically resides asymptomatically in the upper respiratory tract in the carriage state but can also evade the immune system of the host and cross the mucosal membrane to cause invasive disease [2]. Bacterial transmission occurs through direct contact of respiratory droplets expelled by infected individuals or asymptomatic carriers [3]. The pathogen has a three times higher colonisation prevalence in individuals in low and middle-income countries (LMICs) compared to those in high-income countries [4,5].

A total of 100 serotypes of S. pneumoniae have been identified to date, based on the composition of their polysaccharide capsule [6], which is one of their major virulent factors required for host immune evasion and colonisation of the upper respiratory tract [7].

There are currently two licensed PCV vaccines, Synflorix $^{\oplus}$ (PCV10, GlaxoSmithKline) and Prevnar $13^{\circledR}$ (PCV13, Pfizer), which contain purified capsular polysaccharides from 10 and 13 pneumococcal serotypes, respectively. PCV10 includes purified capsular polysaccharides from serotypes $1,4,5,6 \mathrm{~B}, 7 \mathrm{~F}, 9 \mathrm{~V}, 14$, $18 \mathrm{C}, 19 \mathrm{~F}$ and $23 \mathrm{~F}$, whilst PCV13 contains the same but with the addition of purified capsular polysaccharide from serotypes 3, 6A and 19A [8, 9]. Several new pneumococcal vaccine candidates are currently in clinical trials. One of these, Pneumosil ${ }^{\circ}$ (PCV10, Serum Institute of India Pvt. Ltd.), is in pre-qualification with the World Health Organization [10] whilst PCV15 (Merck Sharp \& Dohme Corp., Kenilworth, NJ, USA), which is currently in the Phase III clinical trial, contains the same purified capsular polysaccharides as PCV13 serotypes along with serotypes 22F and 33F. The 20vPnC (PCV20, Pfizer), which is also in Phase III clinical trials, containing the same purified capsular polysaccharides as PCV13 serotypes along with serotypes $8,10 \mathrm{~A}, 11 \mathrm{~A}, 12 \mathrm{~F}, 15 \mathrm{~B}, 22 \mathrm{~F}$ and 33F. Both PCV15 and PCV20 have shown consistent safety profiles compared to currently available PCVs [11, 12]. Despite the availability of pneumococcal vaccines, LMICs face barriers to their introduction due to lack of country-specific data on disease burden and circulating serotypes and the cost of the vaccines [13-15].

GAVI, the Vaccine Alliance, provides free access to vaccines for low-income countries but, as an uppermiddle-income country, Malaysia is not eligible for this initiative $[16,17]$. There has been much delay in implementing pneumococcal vaccination under the Malaysian NIP, lagging behind even the neighbouring Southeast Asian countries, including Laos, Cambodia and the
Philippines (some who have received support from GAVI). Although many LMIC countries have introduced PCV, Malaysia had only previously offered PCV as an optional vaccine in the private healthcare sector $[18,19]$. Due to the high cost associated with PCVs (about RM1, 000 or USD240 for a complete four-dose course of PCV13, which is equivalent to about RM300-350 per dose), only families afford to do so would consider pneumococcal vaccination, therefore resulting in low coverage across the country [14].

There is relatively little information on pneumococcal epidemiology across Southeast Asia and Malaysia, which is concerning due to the rise in antimicrobial resistance and risk associated with pneumococcal infection [16]. In Malaysia, pneumococcal meningitis alone contributes to 2809 cases annually which is significantly higher than those recorded in neighbouring countries Singapore and Thailand [20]. Here we provide an update on the distribution of pneumococcal serotypes from IPD, non-IPD and carriage cases in Malaysia.

\section{Methods}

The online databases PubMed and Scopus were searched for pre-existing literature on pneumococcal serotype prevalence in Malaysia. Reference lists of relevant articles were also searched for relevant articles not found in the database search. No lower date limit was set to maximise the number of potential articles and the search included those published up to 10th November 2020. Search terms included: 'SE Asia*', 'South East Asia*', Southeast Asia"', 'Southeastern Asia*', 'Streptococcus pneumoniae', 'S pneumoniae', 'pneumococc"', 'pneumonia', 'serotype ${ }^{*}$ ', 'serogroup"', 'seroprevalence' and 'Malaysia' separated by the binary operators 'OR' and 'AND'. Article titles and abstracts were searched with these terms to identify potential sources of data. Grey literature (Malaysian Ministry of Health, WHO website) was also searched.

Inclusion criteria included full texts that reported $S$. pneumoniae serotypes in Malaysia, those who reported invasive disease (IPD), non-invasive disease (non-IPD) and carriage studies, as well as those reporting all age groups and genders. Both serogroup and serotype data were included. Exclusion criteria included those studies that were not written in English, non-Malaysian studies, animal studies, case studies, reviews, articles on biochemical techniques or genetics for serotyping, and studies that only reported case numbers or antibody levels without specifying the pneumococcal serotypes.

From the initial search, returned articles were scanned for duplicates, which were then removed. Titles and abstracts were scrutinised, and any articles deemed irrelevant were removed. The full texts of the remaining articles were then reviewed based on the inclusion/ 
exclusion criteria. Of the eligible articles, data were extracted and summarised in a single table. Serotypes were also grouped into age categories, including under 5 years, over 5 years and unreported. The unreported category represents the ages that were not disclosed in the studies or did not fit the age groupings.

Serotype data were grouped into three categories, including IPD, non-IPD and carriage. Within these categories, serotypes were categorised further into vaccine types (VTs), which were those serotypes found in the PCVs, vaccine-related types (VRT), non-vaccine types (NVTs), non-typeable (NT) strains, which were 'unencapsulated' serotypes, and unknown (N/A) serotypes, which are those that could not be determined through conventional methods or from studies that did not explicitly report the specific serotypes. Serotype prevalence with 95\% confidence intervals was calculated using
Microsoft Excel 2019. Graphical representation of serotype distribution was performed using Prism 8 for Windows (GraphPad Software, Inc.).

\section{Results}

One hundred and fifty-four articles were returned from the database search (Fig. 1), 25 of which were duplicates, with one article identified from the reference lists and two from the Google search. No articles were identified from the grey literature. The final analysis included 18 articles (Table 1), with data collected from 1989 to 2017. Eleven of the 18 studies analysed included isolates from invasive disease. Serotype data from a total of 2040 pneumococcal isolates were extracted from the articles and separated by source category and by the age of the cases, with 1008 isolates from IPD, 583 from non-IPD and 299 from carriage (Table 2).

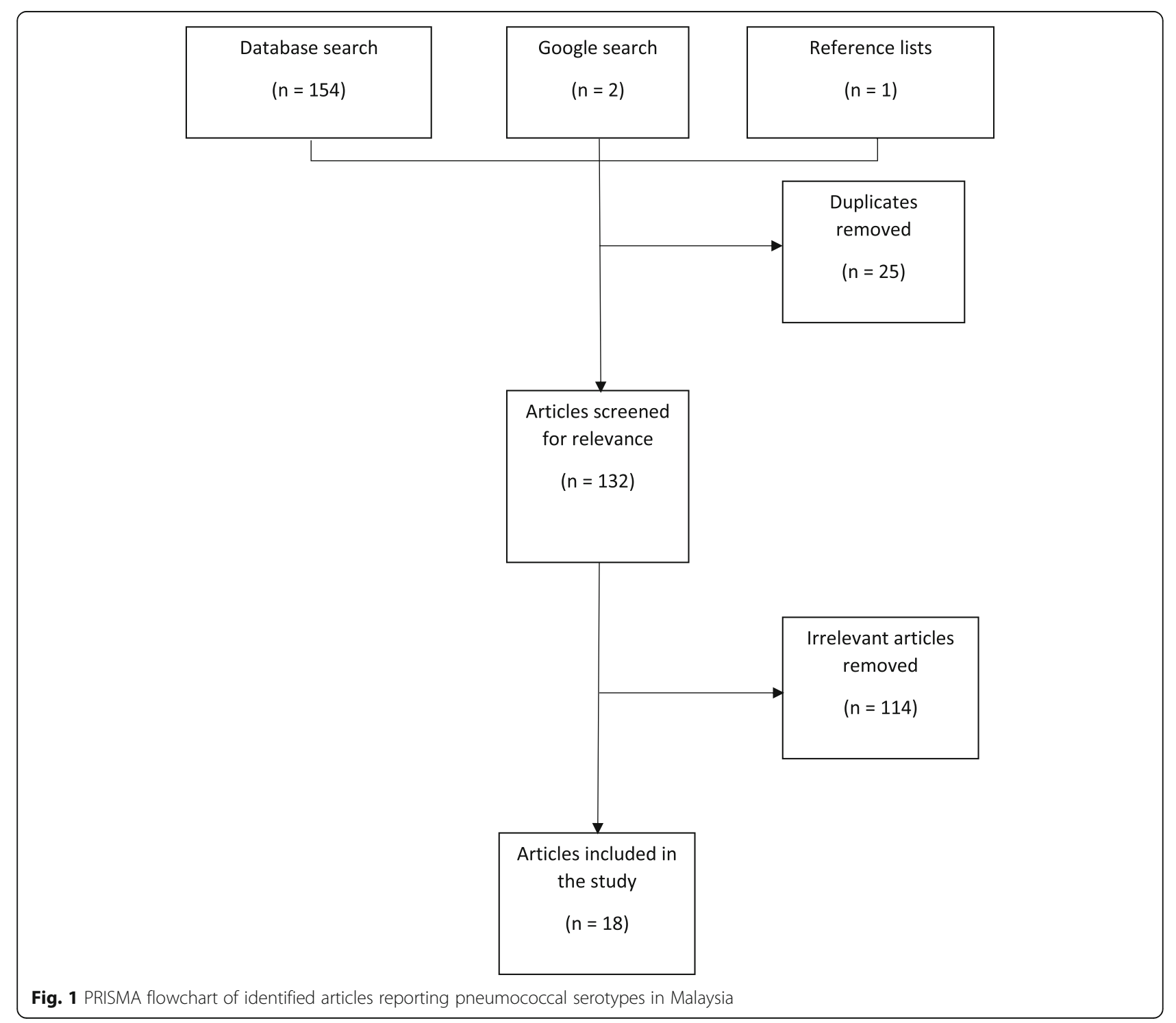




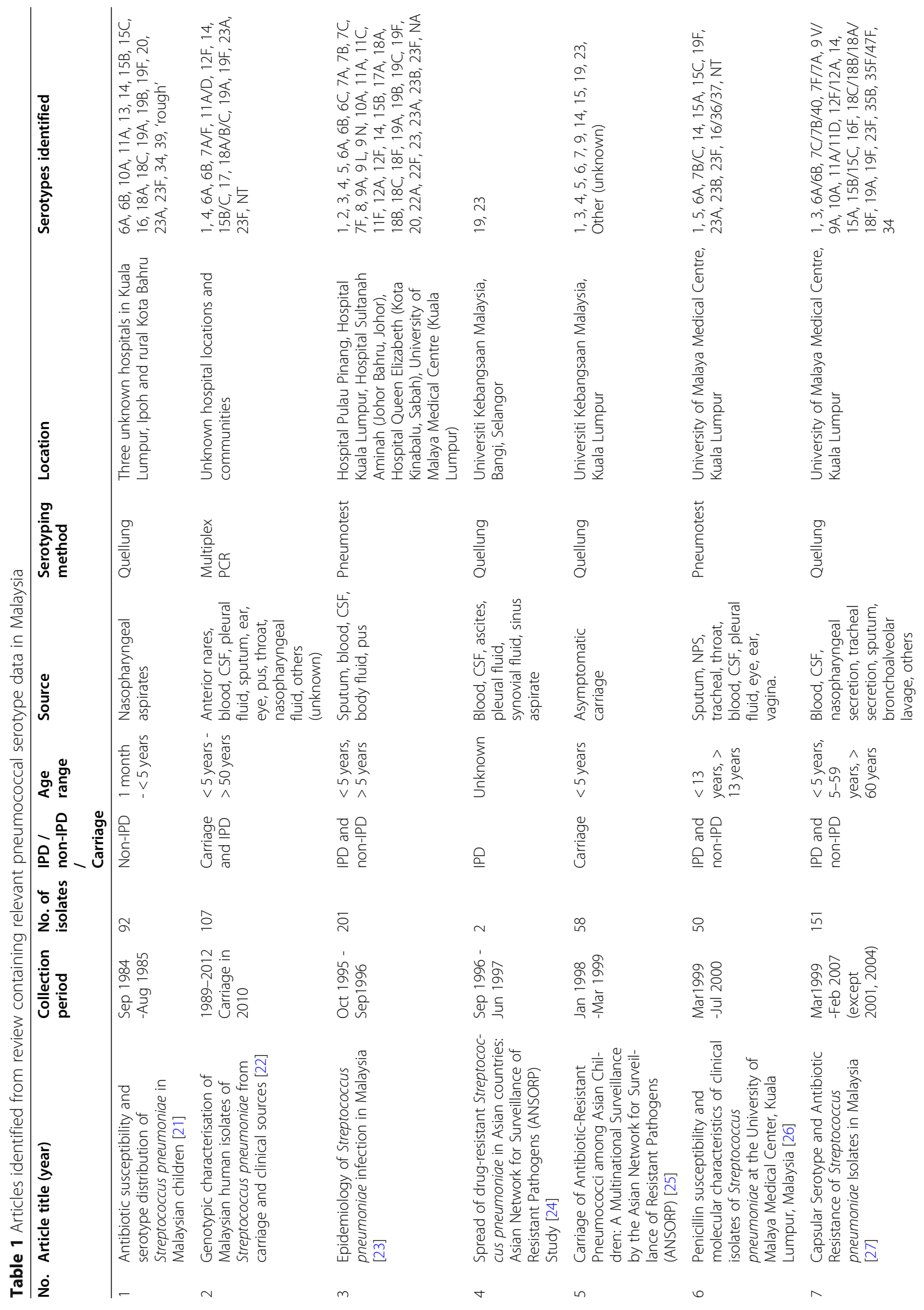




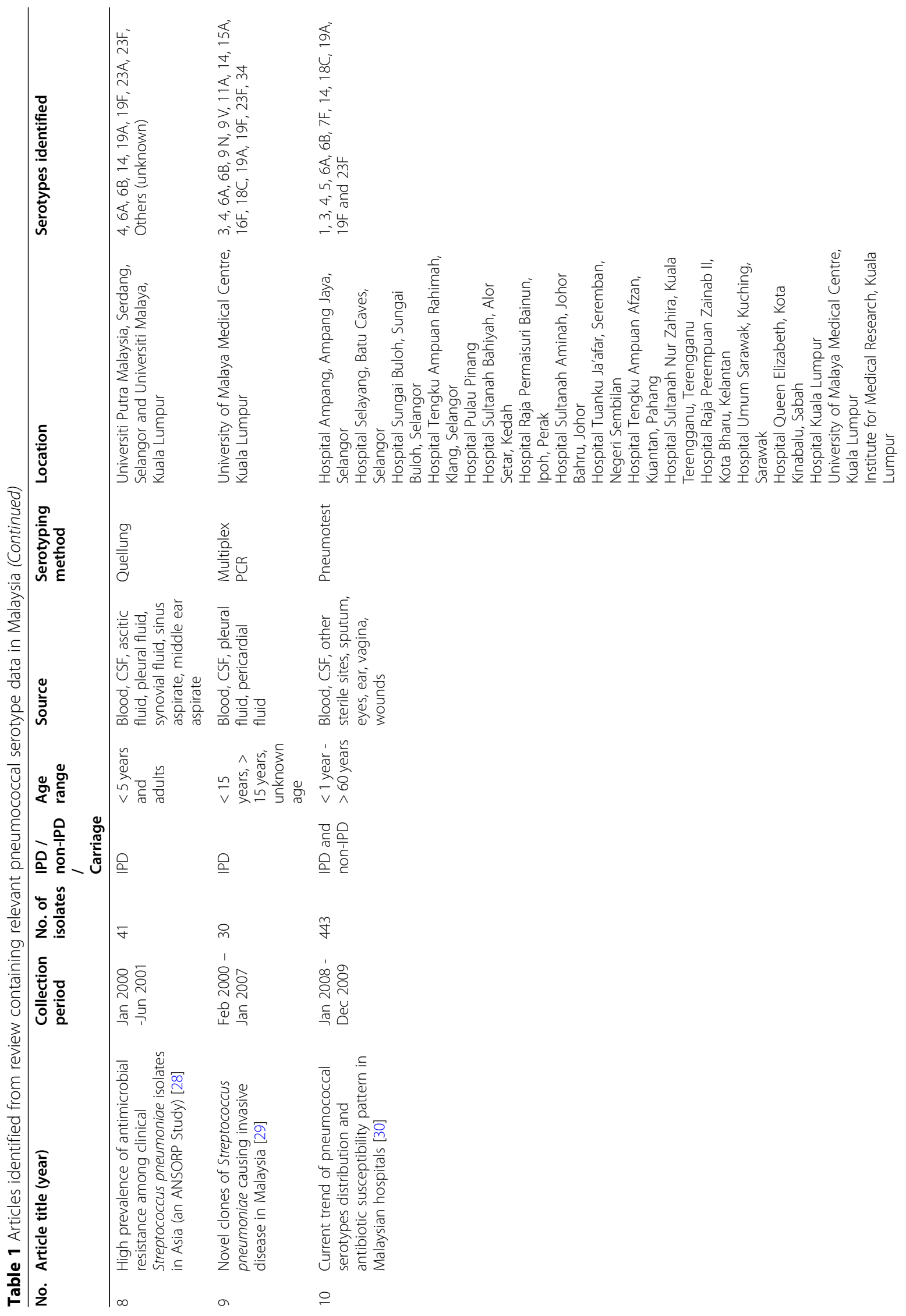




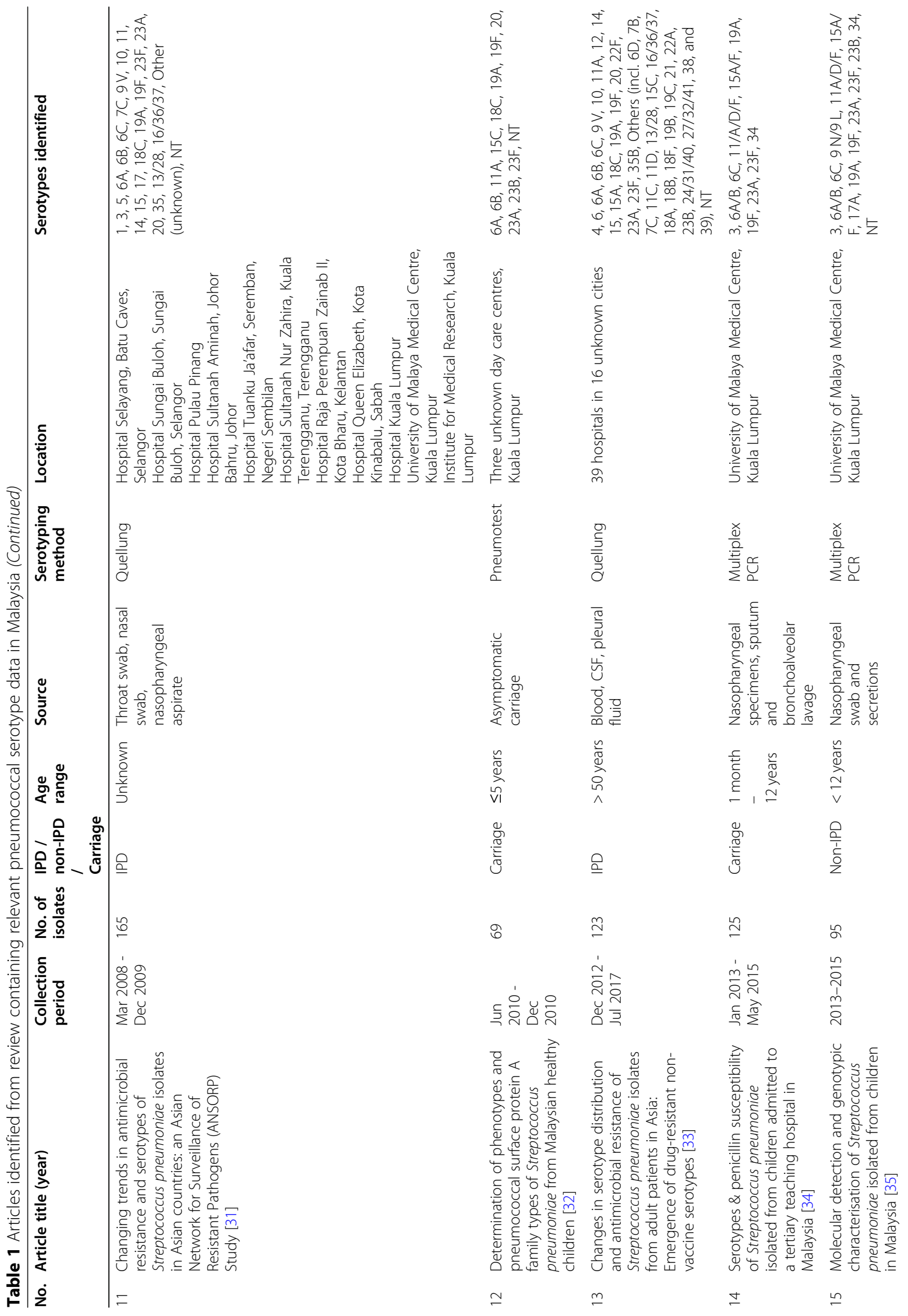




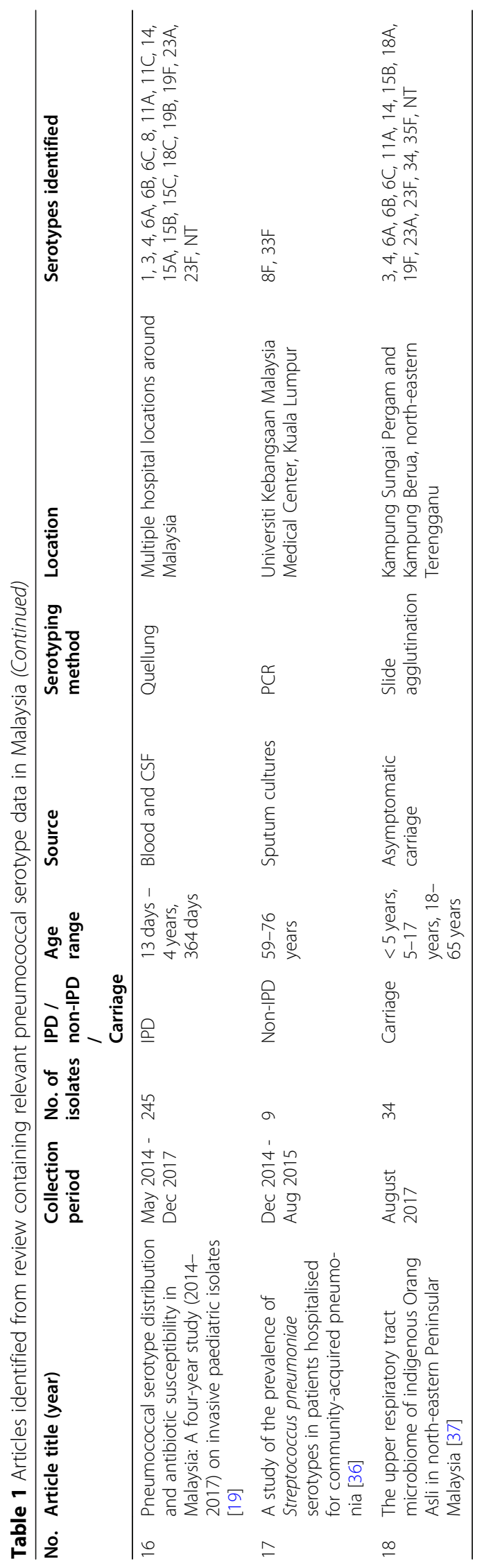


Table 2 Serotype counts across carriage, non-IPD and IPD studies

\begin{tabular}{|c|c|c|c|c|c|c|c|c|c|c|c|}
\hline \multirow[t]{2}{*}{ Country } & \multirow[t]{2}{*}{ Serotype } & \multicolumn{3}{|l|}{ Carriage } & \multicolumn{3}{|l|}{ Non-IPD } & \multicolumn{3}{|l|}{ IPD } & \multirow[b]{2}{*}{$\begin{array}{l}\text { Total } \\
\text { Number } \\
\text { of } \\
\text { isolates } \\
\text { per } \\
\text { serotype } \\
\mathrm{N}(\%)\end{array}$} \\
\hline & & $\leq 5 \mathrm{~N}(\%)$ & $>5 \mathrm{~N}(\%)$ & $\begin{array}{l}\text { Unreported } \\
\mathrm{N}(\%)\end{array}$ & $\leq 5 \mathrm{~N}(\%)$ & $>5 \mathrm{~N}(\%)$ & $\begin{array}{l}\text { Unreported } \\
\mathrm{N}(\%)\end{array}$ & $\leq 5 \mathrm{~N}(\%)$ & $>5 \mathrm{~N}(\%)$ & $\begin{array}{l}\text { Unreported } \\
\mathrm{N}(\%)\end{array}$ & \\
\hline & PCV10 & & & & & & & & & & \\
\hline \multirow[t]{28}{*}{ Malaysia } & 1 & $0(0.0)$ & $0(0.0)$ & $0(0.0)$ & $0(0.0)$ & $3(1.7)$ & $22(6.3)$ & $6(1.8)$ & $14(4.4)$ & $33(9.4)$ & $78(3.8)$ \\
\hline & 4 & $0(0.0)$ & $1(3.3)$ & $0(0.0)$ & $0(0.0)$ & $4(2.2)$ & $1(0.3)$ & $2(0.6)$ & $9(2.8)$ & $5(1.42)$ & $22(1.1)$ \\
\hline & 5 & $0(0.0)$ & $0(0.0)$ & $0(0.0)$ & $0(0.0)$ & $4(2.2)$ & $0(0.0)$ & $1(0.3)$ & $3(0.9)$ & $7(2.0)$ & $15(0.7)$ \\
\hline & $6 \mathrm{~B}$ & $8(6.1)$ & $4(13.3)$ & $5(2.6)$ & $12(8.1)$ & $10(5.6)$ & $16(4.6)$ & $60(17.8)$ & $24(7.5)$ & $24(6.8)$ & $163(8.0)$ \\
\hline & $7 F$ & $0(0.0)$ & $0(0.0)$ & $0(0.0)$ & $1(0.7)$ & $0(0.0)$ & $1(0.3)$ & $2(0.6)$ & $7(2.2)$ & $3(0.9)$ & $14(0.7)$ \\
\hline & $9 \mathrm{~V}$ & $0(0.0)$ & $0(0.0)$ & $0(0.0)$ & $0(0.0)$ & $0(0.0)$ & $0(0.0)$ & $1(0.3)$ & $3(0.9)$ & $2(0.6)$ & $6(0.3)$ \\
\hline & 14 & $1(0.8)$ & $2(6.7)$ & $1(0.5)$ & $6(4.0)$ & $6(3.4)$ & $8(2.3)$ & 74 (21.9) & $30(9.4)$ & 38 (10.8) & $166(8.1)$ \\
\hline & $18 \mathrm{C}$ & $2(1.5)$ & $0(0.0)$ & $0(0.0)$ & $2(1.3)$ & $6(3.4)$ & $4(1.1)$ & $11(3.3)$ & $7(2.2)$ & $12(3.4)$ & $44(2.2)$ \\
\hline & $19 F$ & $6(4.6)$ & $2(6.7)$ & $46(23.5)$ & $27(18.1)$ & $34(19.1)$ & $84(24.1)$ & $27(8.0)$ & $42(13.2)$ & 45 (12.8) & $313(15.3)$ \\
\hline & $23 \mathrm{~F}$ & $13(9.9)$ & $2(6.7)$ & $26(13.3)$ & $15(10.1)$ & $8(4.5)$ & $29(8.3)$ & $20(5.9)$ & $24(7.5)$ & $29(8.2)$ & $166(8.1)$ \\
\hline & \multicolumn{11}{|l|}{ PCV13 } \\
\hline & 3 & $1(0.8)$ & $1(3.3)$ & $2(1.0)$ & $1(0.7)$ & $6(3.4)$ & $12(3.4)$ & $4(1.2)$ & $17(5.3)$ & $9(2.6)$ & $53(2.6)$ \\
\hline & $6 \mathrm{~A}$ & $21(16.0)$ & $1(3.3)$ & $13(6.6)$ & $21(14.1)$ & $6(3.4)$ & $2(0.6)$ & $36(10.7)$ & $17(5.3)$ & $16(4.5)$ & $133(6.5)$ \\
\hline & $19 A$ & $8(6.1)$ & $0(0.0)$ & $14(7.1)$ & $10(6.7)$ & $4(2.2)$ & $7(2.0)$ & $38(11.2)$ & $31(9.7)$ & $26(7.4)$ & $138(6.8)$ \\
\hline & \multicolumn{11}{|l|}{ PCV15 } \\
\hline & $22 \mathrm{~F}$ & $0(0.0)$ & $0(0.0)$ & $0(0.0)$ & $0(0.0)$ & $0(0.0)$ & $3(0.9)$ & $0(0.0)$ & $1(0.3)$ & $0(0.0)$ & $4(0.2)$ \\
\hline & $33 \mathrm{~F}$ & $0(0.0)$ & $0(0.0)$ & $0(0.0)$ & $0(0.0)$ & $0(0.0)$ & $0(0.0)$ & $0(0.0)$ & $0(0.0)$ & $0(0.0)$ & $0(0.0)$ \\
\hline & \multicolumn{11}{|l|}{ PCV20 } \\
\hline & 8 & $0(0.0)$ & $0(0.0)$ & $0(0.0)$ & $0(0.0)$ & $0(0.0)$ & $0(0.0)$ & $1(0.3)$ & $0(0.0)$ & $1(0.3)$ & $2(0.1)$ \\
\hline & $10 \mathrm{~A}$ & $0(0.0)$ & $0(0.0)$ & $0(0.0)$ & $2(1.3)$ & $0(0.0)$ & $4(1.1)$ & $0(0.0)$ & $0(0.0)$ & $1(0.3)$ & $7(0.3)$ \\
\hline & $11 \mathrm{~A}$ & $3(2.3)$ & $1(3.3)$ & $0(0.0)$ & $3(2.0)$ & $0(0.0)$ & $3(0.9)$ & $3(0.9)$ & $2(0.6)$ & $0(0.0)$ & $15(0.7)$ \\
\hline & $12 \mathrm{~F}$ & $0(0.0)$ & $0(0.0)$ & $1(0.5)$ & $0(0.0)$ & $0(0.0)$ & $0(0.0)$ & $0(0.0)$ & $0(0.0)$ & $0(0.0)$ & $1(0.05)$ \\
\hline & $15 B$ & $0(0.0)$ & $0(0.0)$ & $0(0.0)$ & $5(3.6)$ & $0(0.0)$ & $2(0.6)$ & $1(0.3)$ & $0(0.0)$ & $0(0.0)$ & $8(0.4)$ \\
\hline & VRT & $51(38.9)$ & $7(23.3)$ & $46(23.5)$ & $7(4.7)$ & $1(0.6)$ & 75 (21.6) & $17(5.0)$ & $13(4.1)$ & 48 (13.6) & $265(13.0)$ \\
\hline & NVT & $1(0.8)$ & $3(10.0)$ & $9(4.6)$ & $16(10.7)$ & $8(4.5)$ & $30(8.6)$ & $1(0.3)$ & $12(3.8)$ & $29(8.2)$ & $109(5.3)$ \\
\hline & NT & $2(1.5)$ & $6(20.0)$ & $33(16.8)$ & $2(1.3)$ & $21(11.8)$ & $21(6.0)$ & $16(4.7)$ & $11(3.5)$ & $16(4.5)$ & $128(6.3)$ \\
\hline & Unknown & $14(10.7)$ & $0(0.0)$ & $0(0.0)$ & 19 (12.8) & $57(32.0)$ & $24(6.9)$ & $17(5.0)$ & $51(16.0)$ & $8(2.3)$ & $190(9.3)$ \\
\hline & Total & $131(100)$ & $30(100)$ & $196(100)$ & $149(100)$ & $178(100)$ & $348(100)$ & $338(100)$ & $318(100)$ & 352 (100) & $2040(100)$ \\
\hline
\end{tabular}

VRT Vaccine Related, Types NVT Non-Vaccine Types, NY Non-Typeable, PCV Pneumococcal Conjugate Vaccine. IPD Invasive Pneumococcal Disease. Non-IPD NonInvasive Pneumococcal Disease

One thousand and eight (49.4\% [95\%CI: 47.2-51.6]) isolates were identified from invasive disease studies, 675 isolates (33.1\%, [95\%CI: 31.1-35.2]) from non-invasive disease studies and 357 isolates from carriage studies (17.5\%, [95\%CI: 15.9-19.2]). Across all studies, the most common serotypes were 19F $(n=313,15.3 \%$ [95\%CI: 13.8-17.0]), 23F $(n=166,8.1 \%$ [95\%CI: 7.0-9.4]), 14 $(n=166,8.1 \% \quad[95 \% \mathrm{CI}: \quad 7.0-9.4]), \quad 6 \mathrm{~B} \quad(n=163,8.0 \%$ [95\%CI: 6.9-9.2]) and 19A $(n=138,6.8 \%$ [95\%CI: 5.87.9]). Non-vaccine types accounted for $n=109$ (5.3\%, [95\%CI: 4.4-6.4]) isolates. PCV10, PCV13, PCV15 and
PCV20 coverage accounted for $48.4 \%$ [95\%CI: $46.2-$ 50.6], 64.3\% [95\%CI: 62.2-66.3], 64.5\% [95\%CI: 62.4$66.5]$ and $66.1 \%$ [95\%CI: 64.0-68.1] respectively. Unknown serotypes made up $n=190$ (9.3\% [95\%CI: 8.110.7]) of total isolates. Non-typeables made up $n=128$ (6.3\% [95\%CI: 5.3-7.4]) of total isolates.

The most common serotypes found in carriage studies were 19F ( $n=54,15.1 \%$ [95\%CI: $11.8-19.2]), 23 \mathrm{~F}(n=41$, 11.5\% [95\%CI: 8.6-15.2]), 6A $(n=35,9.8$ [95\%CI: 7.1$13.3])$ and $19 \mathrm{~A}(n=22,6.2 \%$ [95\%CI: 4.1-9.2]) and 6B $(n=17,4.8 \% \quad[95 \% \mathrm{CI}: 3.0-7.5])$. Non-vaccine types 
accounted for $n=13$ (3.6\%, [95\%CI: 2.1-6.1]) isolates. PCV10, PCV13, PCV15 and PCV20 coverage accounted for $33.3 \%$ [95\%CI: $28.6-38.4$ ], 50.4\% [95\%CI: 45.3-55.6], 50.4\% [95\%CI: 45.3-55.6] and 51.8\% [95\%CI: 46.6-57.0] respectively.

The most common serotypes across non-IPD studies were 19F $(n=145,21.5 \%$ [95\%CI: $18.5-24.7$ ]), 23F $(n=$ 52, 7.7 [95\%CI: 5.9-10.0]), 6B $(n=38,5.6 \%$ [95\%CI: 4.17.6]), 6A $(n=29,4.3 \%$ [95\%CI: 3.0-6.1]) and $1(n=25$. 3.7\% [95\%CI: 2.5-5.4]). Non-vaccine types accounted for $n=44$ (6.5\% [95\%CI: 4.9-8.6]) isolates. PCV10, PCV13, PCV15 and PCV20 coverage accounted for 44.9\% [95\%CI: 41.2-48.7], $55.1 \%$ [95\%CI: 51.3-58.8], 55.6\% [95\%CI: $51.8-59.3]$ and $58.4 \%$ [95\%CI: $54.6-62.0]$ respectively.

The most common serotypes found in IPD studies were $14(n=142,14.1 \%$ [95\%CI: $12.1-16.4]), 19 \mathrm{~F}(n=$ 114, 11.3\% [9.5-13.4]), 6B $(n=108,10.7 \%$ [95\%CI: $9.0-$ 12.8]), 19A $(n=95,14.1 \%$ [95\%CI: 11.7-16.9]) and 6A $(n=69,6.8 \% \quad[95 \%$ CI $5.4-8.6])$. Non-vaccine types accounted for $n=42(4.2 \%$ [95\%CI: 3.1-5.6]) isolates. PCV10, PCV13, PCV15 and PCV20 coverage accounted for $56.1 \%$ [95\%CI: $53.0-59.1$ ], $75.3 \%$ [95\%CI: 72.5-77.9], 75.4\% [95\%CI: 72.6-78.0] and 76.3\% [95\%CI: 73.6-78.8] respectively.

Non-typeable serotypes made up $n=128 \quad(6.3 \%$ [95\%CI: 5.3-7.4]) of the total isolates, with carriage studies reporting $n=41$ (11.5\%, [95\%CI: 8.6-15.2]) isolates, non-IPD studies reporting $n=44 \quad(6.4 \%$, [95\% CI: $4.8-$ 8.5]) isolates and IPD studies reporting $n=43$ (4.3\%, [95\%CI: 3.2-5.7]) isolates.

Figure 2 shows the distributions of the VT serotypes, alongside VRT serotypes and serogroups, as well as the non-typeable strains and non-vaccine types across IPD, non-IPD and carriage studies.

\section{Discussion}

This study aimed to review the epidemiology of pneumococcal serotypes across Malaysia and to calculate the serotype coverage for currently available PCVs and for PCV15 and PCV20 in clinical trials. Currently, there is limited data on serotype prevalence for IPD and nonIPD in the country, and carriage studies are rarely undertaken. Moreover, pneumococcal carriage data from the Malaysian health services are rarely published and therefore, ad hoc studies have taken place in academic centres without a national approach to surveillance. There were limited studies that investigated non-IPD and carriage in children under five years of age, a critical population when studying the epidemiology of the disease. The most common serotypes are all covered by PCV13, with PCV10 covering four of the five most common serotypes across all isolate sources. PCV13 coverage of serotypes from all isolate sources was calculated at $64.3 \%$, lower than a previous estimate [16].

Serotype 14 was shown to be the most common serotype in invasive disease studies when in comparison, carriage studies report very few isolates. Serotype 14 is known to be associated with childhood disease [38]. The distribution of serotypes across the carriage, noninvasive and invasive disease studies may be associated with the age of the subjects and that the reporting of serogroups may not reflect the differences in serotype invasiveness potential, also rank order of serotypes may not also be correlated with invasiveness [39].

Synflorix ${ }^{\circ}$ contains protein D from non-typeable Haemophilus influenzae (NTHi) that acts as a carrier for pneumococcal serotypes, which may offer broader protection against acute otitis media (AOM) [40] as NTHi infection is one of the most common causes of, alongside pneumococcal infection, of AOM in children [41]. PCV13 also offers protection against pneumococcusrelated AOM through the immunogenic effects of pneumococcal vaccination [42]. However, an indirect effect of PCV13 implementation is a niche disruption that leads to the increased carriage of NTHi in children [43], but evidence for this is mixed [44]. Synflorix may also offer cross-reactivity with serotype 19A [45] as shown in a mouse model through a cross-protection mechanism with serotype 19F-specific IgG antibodies [46, 47], although the response to 19A was significantly lower than the $19 \mathrm{~F}$ response. As we have shown 19A to be a prevalent serotype in both IPD and across all studies, the potential for additional serotype protection is of importance within Malaysia.

Serotype 19A has been seen to increase postvaccination as described previously [48-51] and has been found to be one of the most prevalent serotypes post-PCV7 implementation globally [52]. Serotype 19A also has a high invasive potential, which can result in severe disease in those who have not been vaccinated against the serotype [53]. The increase in invasive disease caused by non-vaccine types, including 19A not covered by PCV10, might also be related to factors including vaccine coverage across the country, comorbidities, antibiotic usage and carriage of pneumococci [54]. As PCV10 becomes routinely taken within Malaysia, surveillance must be continued to monitor any changes in serotype prevalence which has been seen in other countries, as previously mentioned. Serotype 19A was found to be one of the most prevalent $(n=95,14.1 \%$ [95\% CI: 11.7-16.9]) in invasive disease studies. This is concerning as the newly implemented PCV10 does not cover $19 \mathrm{~A}$, therefore it is possible that a rise in this serotype is seen as other vaccine types reduce. Monitoring of serotype distribution as vaccination becomes widespread is needed to track serotype distribution changes. 

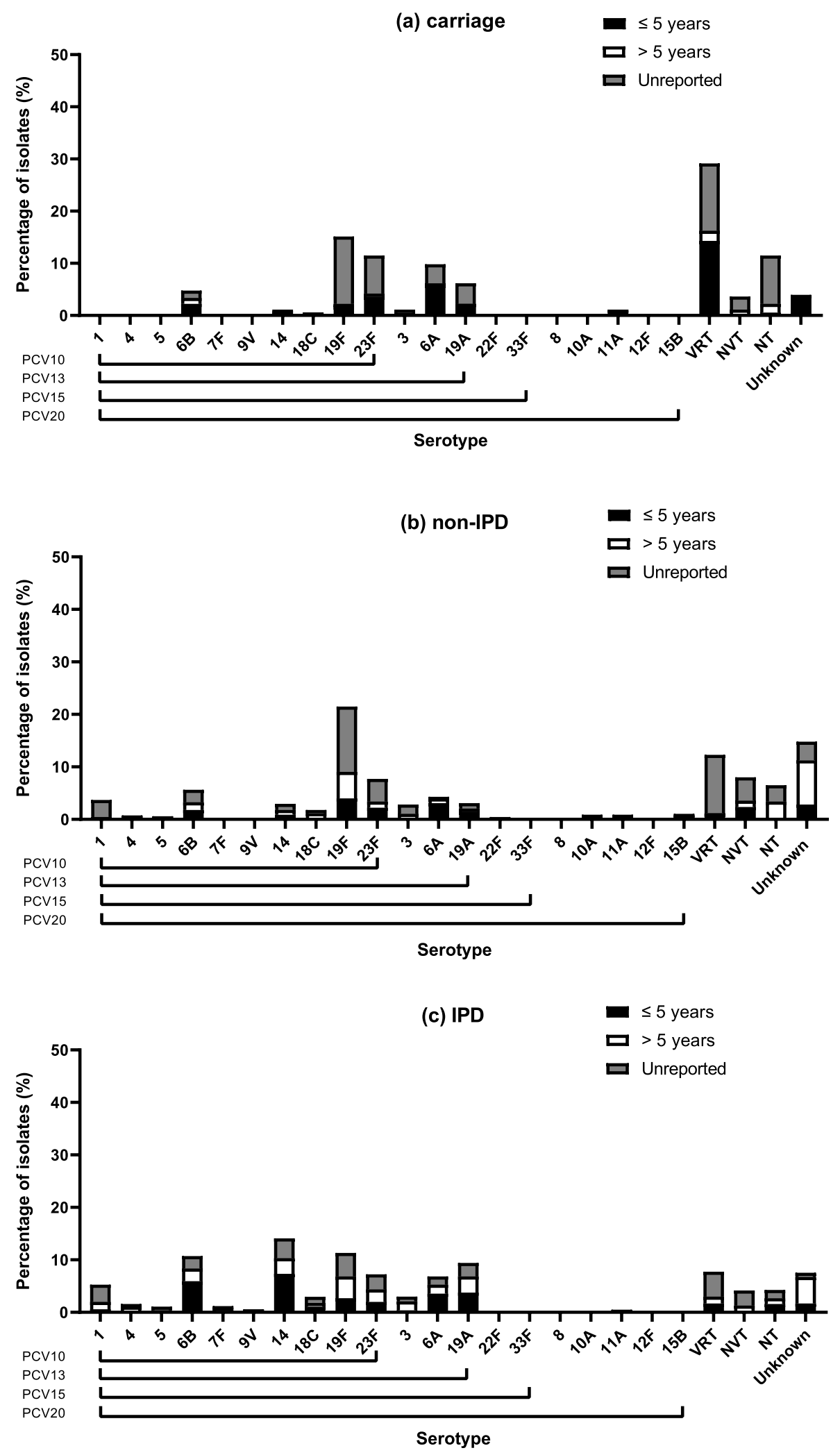

Fig. 2 (See legend on next page.) 
(See figure on previous page.)

Fig. 2 Serotype distributions of S. pneumoniae over (a) carriage, (b) non-invasive disease (non-IPD) and (c) invasive disease (IPD) studies. Data shows number of isolates for $\leq 5$ years, $>5$ years and unreported (not disclosed or does not fit the age categories). Vaccine-related serotypes represent those that are related to the serotypes found in PCVs. VRT = vaccine-related types, NVT = non-vaccine type, NT= non-typeable.

Unknown serotypes are those that were not explicitly reported or those that failed the serotyping process

Eight of the studies included in this analysis used Quellung reaction as their serotyping technique. Quellung reaction is the gold standard for serotyping; however, due to the high cost of the antisera this method may not be feasible in low-resource settings [55]. Another method used in four of the studies was multiplex PCR, which has the benefit of being cost-effective and easy to implement; however, it can be difficult to differentiate between some specific serotypes among other variants from the serogroup [56].

Non-typeable (NT) pneumococcal isolates formed 6.3\% of the total serotypes reported. Typically, NT pneumococci are implicated in non-IPD [57]; this effect was seen in this analysis, with NT isolates making up $6.5 \%$ of the total non-IPD serotypes compared to $4.3 \%$ of IPD serotypes which suggests non-encapsulated pneumococci are not common for invasive disease cases.

PCV implementation realises several benefits. Studies on the estimated economic impact from PCV introduction in Malaysia [58-60] showed that the introduction of PCV13 into the NIP would be cost-effective and is expected to lead to the reduction in pneumococcal disease burden, as seen with that reported in several countries $[31,61]$. Vaccination may also lead to a reduction in antibiotic resistance. Malaysian public and private healthcare providers extensively use antibiotics, especially in the diagnosis of upper respiratory tract infections (49.2\%) [62], thus increasing the risk of resistance selection against $S$. pneumoniae as well as other carriage microbiome. Malaysia has shown pneumococcal isolates displaying antibiotic resistance $[18,33]$, including persistently high penicillin resistance [28] however, PCV vaccination has been shown to reduce resistant serotype prevalence [63].

Many of the studies reviewed were limited in sample size and duration; seven of them had included only isolates from Kuala Lumpur, a highly urbanised area that do not give an accurate representation of the population across the country, thereby failing to offer an accurate representation of pneumococcal epidemiology. There is a need for robust, multi-centre studies, with a large sample size across the country to gain a more accurate representation of the pneumococcal epidemiology. This is especially the case for East Malaysia located on the Borneo island with a different socio-demographic population distribution than Kuala Lumpur in Peninsular Malaysia. Some studies reported serogroups without undergoing further serotyping, and some reported 'unknown' serotypes, hampering the reporting of specific serotypes and does not give the full picture of serotype distribution. Unknown serotypes add no value to the study as they cannot be characterised, therefore the vaccine coverage calculations represent the lowest theoretical coverage, as the unknown serotypes were classified as not belonging to the serotypes covered by the PCVs.

Invasive disease sources came from sterile sites, mainly blood and cerebrospinal fluid. Non-invasive disease sources included non-sterile sites, such as nasopharyngeal swabs and sputum. Two studies reported noninvasive isolates from the eye and vagina $[26,30]$ and three studies included swabs from the ear [26, 28, 30].

The lack of data and the limited number of studies prevented an age analysis from being carried out, nor a study on anatomical site serotypes. Unfortunately, the lack of unbiased studies makes conclusions on epidemiological burden difficult, as the studies included present populations that would not be representative of the country. Selection bias within the studies can give a false picture of serotype distribution as studies may focus on only serotypes from severe cases of disease. Scale, geographical location and the study time differences can affect the representativeness of the data [27]. Studies with more recent collection periods will provide a better insight into current epidemiological trends. Incidence of invasive disease was lacking in the studies. Incidence rates were not able to be calculated with populationbased studies as relative risk cannot be calculated when starting with a diseased population and a non-diseased population. A study from 1999 [23] reports the incidence of pneumococcal meningitis at 1.5 cases per 100 , 000 in the Malaysian population, but no other articles included in this study report invasive pneumococcal disease incidence.

Many studies in our analysis included isolates from hospitals or medical centres. Although hospitals provide cohorts of individuals who might have IPD or non-IPD, the population does not truly reflect the country demographics. Potential limitations with hospital-based studies include difficulties in finding control groups, risk of results duplication if patients move between hospitals and difficulties in defining the population. This study has highlighted the need for carriage studies within Malaysia. In the past 20 years, only one small-scale study on daycare children in Kuala Lumpur has been reported [32]. Most other studies were clinically related, with only two multi-centre surveillance studies reported by the 
Institute for Medical Research (IMR) involving patient cohorts from 2008 to 2009 and 2014-2017, respectively $[13,30]$. Unfortunately, no further data is available on childhood carriage from other geographical regions in Malaysia. In fact, the paucity of such studies and the need for pneumococcal carriage surveillance in Malaysia has been clearly highlighted [64]. Pneumococcal surveillance programmes are not only needed to assess the pneumococcal burden and the progress of immunisation initiative but also alerts the health bodies and scientific community on changes in serotype distribution and offers a view into herd immunity effects in the population [64-67]. The implementation of a pneumococcal surveillance programme is vital for the understanding of pneumococcal population dynamics in Malaysia, especially in children under five years of age as we are now into the post-PCV era following implementation of PCV10 into the routine NIP [16].

\section{Conclusion}

This study provides a comprehensive insight into the allinclusive pneumococcal serotype prevalence in Malaysia since 1989 before the introduction of PCV10 under the Malaysian NIP in late 2020. Our results highlight the need for continued surveillance of pneumococcal seroepidemiology and disease prevalence, as it is difficult to accurately estimate the disease burden and serotype coverage of pneumococcal vaccines. New conjugate vaccines in development such as PCV15 and PCV20 will offer broader serotype coverage, but whether these would confer a significant added protective efficacy over the existing pneumococcal vaccine to the Malaysian population would need continued monitoring, especially in the coming years following a potential serotype shift in the post-PCV era as observed in many other countries.

\section{Abbreviations}

IPD: Invasive pneumococcal disease; LMIC: Low and middle-income countries; Non-IPD: Non-invasive pneumococcal disease; NT: Non-typeable; NTHi: Non-typeable Haemophilus influenzae; NVT: Non-vaccine type; PCV: Pneumococcal conjugate vaccine; VT: Vaccine type

\section{Acknowledgements}

Not applicable.

\section{Authors' contributions}

SCC planned the review. AL wrote the initial draft and conducted the data analysis. DWC and SCC reviewed the draft manuscript and directed the edits. DWC, SCC, CFL, ESGC and MNMD reviewed the final draft and gave recommendations to additional research, structure and clarity. AL made corrections and additions to the final draft and made the submission. The author(s) read and approved the final manuscript.

\section{Funding}

No funding was available for this project.

\section{Availability of data and materials}

All data generated or analysed during this study are included in this published article.

\section{Declarations}

Ethics approval and consent to participate

Not applicable.

\section{Consent for publication}

Not applicable.

\section{Competing interests}

SCC acts as principal investigator on studies conducted on behalf of University Hospital Southampton NHS Foundation Trust and the University of Southampton that are sponsored by vaccine manufacturers but receives no personal payments. SCC has received financial assistance from vaccine manufacturers to attend conferences. SCC has participated in advisory boards for vaccine manufacturers but receives no personal payments. DWC was a post-doctoral researcher on projects funded by Pfizer and GSK between April 2014 and 20th October 2017. All other authors have no conflicts of interest.

\section{Author details}

${ }^{1}$ Faculty of Medicine and Institute for Life Sciences, Infectious Disease Epidemiology Group, University of Southampton, Mailpoint 814, Level C, Sir Henry Wellcome Laboratories, South Block, University Hospital Southampton Foundation NHS Trust, Southampton SO16 6YD, UK. ${ }^{2}$ School of Biosciences, Faculty of Science and Engineering, University of Nottingham Malaysia, Jalan Broga, 43500 Semenyih, Selangor, Malaysia. ${ }^{3}$ Department of Biological Science, Faculty of Science, Universiti Tunku Abdul Rahman (UTAR), Kampar Campus, 31900 Kampar, Perak, Malaysia. ${ }^{4}$ Department of Biomedical Sciences, Faculty of Medicine and Health Sciences, Universiti Putra Malaysia, 43400 Serdang, Selangor, Malaysia. ${ }^{5} \mathrm{NIHR}$ Southampton Biomedical Research Centre, University Hospital Southampton Foundation NHS Trust, Southampton, UK. ${ }^{6} \mathrm{Global}$ Health Research Institute, University of Southampton, Southampton, UK. Institute for Research, Development and Innovation, International Medical University, Kuala Lumpur, Malaysia.

Received: 19 January 2021 Accepted: 12 April 2021

Published online: 25 May 2021

\section{References}

1. WHO, 2014. Pneumococcal Disease. [Online] Available at: https://www.who. int/immunization/diseases/pneumococcal/en/ [Accessed 17 October 2020].

2. Ndlangisa K, du Plessis M, Allam M, Wolter N, de Gouveia L, Klugman KP, et al. Invasive disease caused simultaneously by dual serotypes of streptococcus pneumoniae. J Clin Microbiol. 2017;56(1). https://doi.org/1 0.1128/JCM.01149-17.

3. CDC, 2019. Pneumococcal disease. [Online] Available at: https://www cdc.gov/pneumococcal/clinicians/transmission.html [Accessed 17 October 2020].

4. Ngocho J, et al. Effectiveness of pneumococcal conjugate vaccines against pneumococcal disease among children under five years of age in Africa: a systematic review. PLoS One. 2019;14(2):e0212295. https://doi.org/10.1371/ journal.pone.0212295.

5. Satzke C, Dunne EM, Choummanivong M, Ortika BD, Neal EFG, Pell CL, et al. Pneumococcal carriage in vaccine-eligible children and unvaccinated infants in Lao PDR two years following the introduction of the 13-valent pneumococcal conjugate vaccine. Vaccine. 2019;37(2):296-305. https://doi. org/10.1016/j.vaccine.2018.10.077.

6. Ganaie F, Saad JS, McGee L, van Tonder AJ, Bentley SD, Lo SW, et al. A new pneumococcal capsule type, 10D, is the 100th serotype and has a large cps fragment from an oral streptococcus. mBio. 2020;11(3):e00937-20.

7. Shainheit M, Mule M, Camilli A. The Core promoter of the capsule operon of Streptococcus pneumoniae is necessary for colonization and invasive disease. Infect Immun. 2013;82(2):694-705. https://doi.org/10.1128//Al.012 89-13.

8. Clinicaltrials.gov. Safety and Immunogenicity Study of GlaxoSmithKline (GSK) Biologicals' 10-valent Pneumococcal Conjugate Vaccine. 2018. Available from: https://clinicaltrials.gov/ct2/show/results/NCT00344318?recrs=e\&rslt= With\&cond=PCV10\&rank=7\&view=results. Accessed 22 Dec 2020.

9. Clinicaltrials.gov. Phase 3 Study of 10-valent Pneumococcal Conjugate Vaccine (PNEUMOSIL) in Healthy Infants. 2019. Available from: https://clinica Itrials.gov/ct2/results? cond=\&term=\&type=\&rslt=\&age_v=\&gndr=\&intr $=$ 
\&titles $=\&$ outc $=\&$ spons $=\&$ lead $=\& i d=N C T 03197376 \& c n t r y=\&$ state $=\&$ city $=$

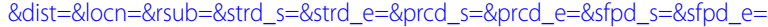
\&rfpd_s=\&rfpd_e=\&lupd_s=\&lupd_e=\&sort= Accessed 22 Dec 2020.

10. PATH. Fact sheet: pneumococcal disease, pneumococcal conjugate vaccines, and PNEUMOSIL $\bullet^{-}$. 2019. Available from: https:/www.path.org/ resources/fact-sheetpneumococcal-disease-pneumococcal-conjugate-va ccines-and-pneumosil/. Accessed 17 Oct 2020.

11. Greenberg D, Hoover PA, Vesikari T, Peltier C, Hurley DC, McFetridge RD, et al. Safety and immunogenicity of 15-valent pneumococcal conjugate vaccine (PCV15) in healthy infants. Vaccine. 2018;36(45):6883-91. https://doi, org/10.1016/j.vaccine.2018.02.113

12. Hurley $D$, et al. Safety, tolerability, and immunogenicity of a 20-Valent pneumococcal conjugate vaccine (PCV20) in adults 60 to 64 years of age. Clin Infect Dis. 2020;ciaa1 045:1-9. https://doi.org/10.1093/cid/ciaa1045

13. Arushothy R, Ahmad N, Amran F, Hashim R, Samsudin N, Rosalina Che Azih C. Pneumococcal serotype distribution and antibiotic susceptibility in Malaysia: a four-year study (2014-2017) on invasive paediatric isolates. Int J Infect Dis. 2019;80:129-33.

14. Le CF, Jefferies JM, Yusof MYM, Sekaran SD, Clarke SC. The epidemiology of pneumococcal carriage and infections in Malaysia. Expert Rev Anti-Infect Ther. 2012;10(6):707-19. https://doi.org/10.1586/eri.12.54.

15. Linus-Lojikip S, Zulaikha F, Mohamed Nor J, Ahamad Romazul N, Hidayah Shamshuddin N, Ngah R, et al. Parents' knowledge on pneumococcal vaccine and opinions on payment strategies in Malaysia. Int I Stud Children Women Elderly Disabled. 2019;8:86-95.

16. Jauneikaite $\mathrm{E}$, Jefferies JM, Hibberd ML, Clarke SC. Prevalence of Streptococcus pneumoniae serotypes causing invasive and non-invasive disease in South East Asia: a review. Vaccine. 2012;30(24):3503-14. https:// doi.org/10.1016/j.vaccine.2012.03.066.

17. GAVI.org. Eligibility. 2021. Available from: https://www.gavi.org/typessupport/sustainability/eligibility. Accessed 05 Jan 2021.

18. Aljunid S, Abuduxike G, Ahmed Z, Sulong S, Muhd Nur A, Goh A. Impact of routine PCV7 (Prevenar) vaccination of infants on the clinical and economic burden of pneumococcal disease in Malaysia. BMC Infect Dis. 2011;11(248): 1-10. https://doi.org/10.1186/1471-2334-11-248.

19. Tricarico S, McNeil HC, Head MG, Cleary DW, Clarke SC. Informing pneumococcal conjugate vaccine policy in middle income countries: the case of Malaysia. Vaccine. 2017;18(35):2288-90

20. Maimaiti N, Lotfizadeh M, Ahmed Z, Rahimi A, Jadoo SA, Al JS. Incidence of pneumococcal meningitis in children less than 5 years of age in Malaysia, Singapore and Thailand: a review. Malays J Public Health Med. 2015;15(1):25-9.

21. Cheong YM, Jegathesan M, Henrichsen J, Wong YH, Ng AJ, Louis A. Antibiotic susceptibility and serotype distribution of Streptococcus pneumoniae in Malaysian children. J Trop Pediatr. 1988;34(4):182-5. https:// doi.org/10.1093/tropej/34.4.182.

22. Shakrin N, Masri S, Taib N, Nordin S, Jamal F, Desa M. Genotypic characterization of Malaysian human isolates of Streptococcus pneumoniae from carriage and clinical sources. Comp Immunol Microbiol Infect Dis. 2014;37(5-6):347-54. https://doi.org/10.1016/..cimid.2014.10.005.

23. Rohani M, Raudzah A, Ng A, Ng P, Zaidatul A, Asmah I, et al. Epidemiology of Streptococcus pneumoniae infection in Malaysia. Epidemiol Infect. 1999; 122(1):77-82.

24. Song JH, Lee NY, Ichiyama S, Yoshida R, Hirakata Y, Fu Y, et al. Spread of drug-resistant Streptococcus pneumoniae in Asian countries: Asian network for surveillance of resistant pathogens (ANSORP) study. Clin Infect Dis. 1999; 28(6):1206-11. https://doi.org/10.1086/514783.

25. Lee N, Song J, Kim S, Peck K, Ahn K, Lee S, et al. Carriage of antibioticresistant pneumococci among Asian children: a multinational surveillance by the Asian network for surveillance of resistant pathogens (ANSORP). Clin Infect Dis. 2001;32(10):1463-9. https://doi.org/10.1086/320165.

26. Desa M, Lin T, Yasin R, Parasakthi N. Penicillin susceptibility and molecular characteristics of clinical isolates of Streptococcus pneumoniae at the University of Malaya Medical Center, Kuala Lumpur. Malaysia International Journal of Infectious Diseases. 2003;7(3):190-7. https://doi.org/10.1016/S1201-9712(03)90051-8.

27. Le C, Palanisamy N, Mohd Yusof M, Sekaran S. Capsular serotype and antibiotic resistance of Streptococcus pneumoniae isolates in Malaysia. PLoS One. 2011;6(5):e19547. https://doi.org/10.1371/journal.pone.0019547.

28. Song J, Jung S, Ko KS, Kim NY, Son JS, Chang H, et al. High prevalence of antimicrobial resistance among clinical Streptococcus pneumoniae isolates in Asia (an ANSORP study). Antimicrob Agents Chemother. 2004:48(6):21017. https://doi.org/10.1128/AAC.48.6.2101-2107.2004.
29. Jefferies J, Mohd Yusof M, Devi Sekaran S, Clarke S. Novel clones of Streptococcus pneumoniae causing invasive disease in Malaysia. PLoS One. 2003;9(6):e97912.

30. Rohani M, Zin N, Hussin A, Nawi S, Hanapiah S, Wahab Z, et al. Current trend of pneumococcal serotypes distribution and antibiotic susceptibility pattern in Malaysian hospitals. Vaccine. 2011;29(34):5688-93. https://doi. org/10.1016/j.vaccine.2011.06.004

31. Kim SH, Song JH, Chung DR, Thamlikitkul V, Yang Y, Wang H, et al. Changing trends in antimicrobial resistance and serotypes of Streptococcus pneumoniae isolates in Asian countries: an Asian network for surveillance of resistant pathogens (ANSORP) study. Antimicrob Agents Chemother. 2012; 56(3):1418-26. https://doi.org/10.1128/AAC.05658-11.

32. Yatim M, Masri S, Desa M, Taib N, Nordin S, Jamal F. Determination of phenotypes and pneumococcal surface protein a family types of Streptococcus pneumoniae from Malaysian healthy children. J Microbiol Immunol Infect. 2013;46(3):180-6. https://doi.org/10.1016/j.jmii.2012.04.004.

33. Kim S, Chung D, Song J, Baek J, Thamlikitkul V, Wang H, et al. Changes in serotype distribution and antimicrobial resistance of Streptococcus pneumoniae isolates from adult patients in Asia: emergence of drug resistance non-vaccine serotypes. Vaccine. 2020;38(38):6065-73. https://doi. org/10.1016/.jvaccine.2019.09.065.

34. Subramaniam P, Jabar K, Kee B, Chong C, Nathan A, de Bruyne J, et al. Serotypes \& penicillin susceptibility of Streptococcus pneumoniae isolated from children admitted to a tertiary teaching hospital in Malaysia. Indian J Med Res. 2018;148(2):225-31. https://doi.org/10.4103/ijmr.IJMR_1987_16.

35. Goh SL, Kee BP, Jabar KA, Chua KH, Nathan AM, Bruyne J, et al. Molecular detection and genotypic characterisation of Streptococcus pneumoniae isolated from children in Malaysia. Pathogens Glob Health. 2020;114(1):4654. https://doi.org/10.1080/20477724.2020.1719325.

36. Bahtar A, Abdul Manap R, Ban A. A study of the prevalence of streptococcus pneumoniae serotypes in patients hospitalised for community-acquired pneumonia. Eur Respir J. 2016;48.

37. Cleary D, Morris D, Anderson R, Jones J, Alattraqchi A, A. Rahman $\mathrm{N}$ et al. The upper respiratory tract microbiome of indigenous Orang Asli in northeastern Peninsular Malaysia. Npj Biofilms Microbiomes. 2021;7(1):1-10. https://doi.org/10.1038/s41522-020-00173-5.

38. Sniadack DH, Schwartz B, Lipman J, Bogaerts J, Butler JC, Dagan R, et al. Potential interventions for the prevention of childhood pneumonia: geographic and temporal differences in serotype and serogroup distribution of sterile site pneumococcal isolates from children--implications for vaccine strategies. Pediatr Infect Dis J. 1995;14(6):503-10. https://doi. org/10.1097/00006454-199506000-00007.

39. Brueggemann AB, Peto TEA, Crook DW, Butler JC, Kristinsson KG, Spratt BG. Temporal and geographic stability of the Serogroup-specific invasive disease potential of Streptococcus pneumoniae in children. J Infect Dis. 2004;190(7):1203-11. https://doi.org/10.1086/423820.

40. Kaur R, Casey JR, Pichichero ME. Serum antibody response to three non-typeable Haemophilus influenzae outer membrane proteins during acute otitis media and nasopharyngeal colonization in otitis prone and non-otitis prone children. Vaccine. 2011;29(5):1023-8. https://doi.org/10.1016/j.vaccine.2010.11.055.

41. Clarke C, Bakaletz LO, Ruiz-Guiñazú J, Borys D, Mrkvan T. Impact of protein D-containing pneumococcal conjugate vaccines on non-typeable Haemophilus influenzae acute otitis media and carriage. Expert Rev Vaccines. 2017;16(7):1-14. https://doi.org/10.1080/14760584.2017.1333905.

42. Pichichero M, Kaur R, Scott DA, Gruber WC, Trammel J, Almudevar A, et al. Effectiveness of 13-valent pneumococcal conjugate vaccination for protection against acute otitis media caused by Streptococcus pneumoniae in healthy young children: a prospective observational study. Lancet Child Adolesc Health. 2018;2(8):561-8. https://doi.org/10.1016/S2352-4642(18)30168-8.

43. Cleary D, Devine V, Morris D, Osman K, Gladstone R, Bentley S, et al. Pneumococcal vaccine impacts on the population genomics of nontypeable Haemophilus influenzae. Microbial Genomics. 2018;4(9):e000209. https://doi.org/10.1099/mgen.0.000209.

44. van den Bergh MR, Spijkerman J, Swinnen KM, François NA, Pascal TG, Borys $D$, et al. Effects of the 10-valent pneumococcal nontypeable Haemophilus influenzae protein D- conjugate vaccine on nasopharyngeal bacterial colonization in young children: a randomized controlled trial. Clin Infect Dis. 2012;56(3):e30-9. https://doi.org/10.1093/cid/cis922.

45. Hausdorff WP, Hoet B, Schuerman L. Do pneumococcal conjugate vaccines provide any cross-protection against serotype 19A? BMC Pediatr. 2010;10(4): 1-7. https://doi.org/10.1186/1471-2431-10-4. 
46. Lee H, Nahm MH, Burton R, Kim KH. Immune response in infants to the heptavalent pneumococcal conjugate vaccine against vaccine-related serotypes 6A and 19A. Clin Vaccine Immunol. 2009;16(3):376-81. https://doi. org/10.1128/CVl.00344-08.

47. Jakobsen H, Sigurdsson VD, Sigurdardottir S, Schulz D, Jonsdottir I. Pneumococcal serotype $19 \mathrm{~F}$ conjugate vaccine induces cross-protective immunity to serotype $19 \mathrm{~A}$ in a murine pneumococcal pneumonia model. Infect Immun. 2003;71(5):2956-9. https://doi.org/10.1128/IAI.71.5.2 956-2959.2003.

48. Mott MP, Caierão J, Cunha GR, del Maschi MM, Pizzutti K, d'Azevedo P, et al. Emergence of serotype 19A Streptococcus pneumoniae after PCV10 associated with a ST320 in adult population, in Porto Alegre, Brazil. Epidemiol Infect. 2019;147:e93. https://doi.org/10.1017/S095026881 9000013.

49. Tai SS. Streptococcus pneumoniae serotype distribution and pneumococcal conjugate vaccine serotype coverage among pediatric patients in east and Southeast Asia, 2000-2014: a pooled data analysis. Vaccines (Basel). 2016; 4(1):1-15. https://doi.org/10.3390/vaccines4010004.

50. Moreno GC, Imbachi LF, Leal AL, Moreno VM, Patiño JA, Gutiérrez IF, et al. Emergence of Streptococcus pneumoniae serotype 19A (Spn19A) in the pediatric population in Bogotá, Colombia as the main cause of invasive pneumococcal disease after the introduction of PCV10. Hum Vaccines Immunotherapeutics. 2020;16(9):2300-6. https://doi.org/10.1080/21645515.2 019.1710411

51. Pai R, Moore MR, Pilishvili T, Gertz RE, Whitney CG, Beall B. Active bacterial Core surveillance team. Postvaccine genetic structure of Streptococcus pneumoniae serotype 19A from children in the United States. J Infect Dis. 2005:192(11):1988-95. https://doi.org/10.1086/498043.

52. Mclntosh EDG, Reinert RR. Global prevailing and emerging pediatric pneumococcal serotypes. Expert Rev Vaccines. 2011;10(1):109-29. https://doi. org/10.1586/erv.10.145

53. Hanage WP, Kaijalainen TH, Syrjänen RK, Auranen $K$, Leinonen M, Mäkelä PH, et al. Invasiveness of serotypes and clones of Streptococcus pneumoniae among children in Finland. Infect Immun. 2005;73(1):431-5. https://doi.org/1 0.1128/IAl.73.1.431-435.2005.

54. Izurieta P, Bahety P, Adegbola R, Clarke C, Hoet B. Public health impact of pneumococcal conjugate vaccine infant immunization programs: assessment of invasive pneumococcal disease burden and serotype distribution. Expert Rev Vaccines. 2018;17(6):479-93. https://doi.org/10.1 080/14760584.2018.1413354.

55. Habib M, Porter BD, Satzke C. Capsular serotyping of Streptococcus pneumoniae using the Quellung reaction. J Vis Exp. 2014;84:e51208. https:// doi.org/10.3791/51208.

56. Pai R, Gertz RE, Beall B. Sequential multiplex PCR approach for determining capsular serotypes of Streptococcus pneumoniae isolates. J Clin Microbiol. 2006;44(1):124-31. https://doi.org/10.1128/JCM.44.1.124-131.2006.

57. Langereis J. de Jonge. Non-encapsulated streptococcus pneumoniae, vaccination as a measure to interfere with horizontal gene transfer. Virulence. 2017;8(6):637-9. https://doi.org/10.1080/21505594.2017.1309492.

58. Shafie AA, Ahmad N, Naidoo J, Yoong Foo C, Wong C, Pugh S, et al. Estimating the population health and economic impacts of introducing a pneumococcal conjugate vaccine in Malaysia - an economic evaluation. Hum Vaccines Immunotherapeutics. 2020;16(7):1719-27. https://doi.org/10.1 080/21645515.2019.1701911.

59. Aljunid S, Maimaiti N, Ahmed Z, Nur AM, Md Isa Z, Azmi A, et al. Economic impact of pneumococcal protein-D conjugate vaccine (PHiD-CV) on the Malaysian National Immunization Programme. Value Health Reg Issue. 2014; 3:146-55. https://doi.org/10.1016/j.vhri.2014.04.008.

60. Wu DBC, Roberts C, Lee WWY, Hong LW, Tan KK, Mak V, et al. Costeffectiveness analysis of infant universal routine pneumococcal vaccination in Malaysia and Hong Kong. Hum Vaccines Immunotherapeutics. 2016;12(2): 403-16. https://doi.org/10.1080/21645515.2015.1067351.

61. Dilokthornsakul P, Kengkla K, Saokaew S, Permsuwan U, Techasaensiri C, Chotpitayasunondh T, et al. An updated cost-effectiveness analysis of pneumococcal conjugate vaccine among children in Thailand. Vaccine. 2019;37(32):4551-60. https://doi.org/10.1016/j.vaccine.2019.06.015.

62. Rahman NA, Teng CL, Sivasampu S. Antibiotic prescribing in public and private practice: a cross-sectional study in primary care clinics in Malaysia. BMC Infect Dis. 2016;16(1):208. https://doi.org/10.1186/s12879-016-1530-2.

63. Moore M, Link-Gelles R, Schaffner W, Lynfield R, Lexau C, Bennett N, et al. Effect of use of 13-valent pneumococcal conjugate vaccine in children on invasive pneumococcal disease in children and adults in the USA: analysis of multisite, population-based surveillance. Lancet Infect Dis. 2015;15(3):3019. https://doi.org/10.1016/S1473-3099(14)71081-3.

64. McNeil HC, Clarke SC. Serotype prevalence of Streptococcus pneumoniae in Malaysia - the need for carriage studies. Med J Malays. 2016;71(3):134-8.

65. Satzke C, Turner P, Virolainen-Julkunen A, Adrian PV, Antonio M, Hare KM, et al. Standard method for detecting upper respiratory carriage of Streptococcus pneumoniae: updated recommendations from the World Health Organization pneumococcal carriage working group. Vaccine. 2013; 32(1):165-79. https://doi.org/10.1016/j.vaccine.2013.08.062.

66. Chan J, Nguyen CD, Dunne EM, Mulholland EK, Mungun T, Pomat WS, et al. Using pneumococcal carriage studies to monitor vaccine impact in lowand middle-income countries. Vaccine. 2019;37(43):6299-309. https://doi. org/10.1016/j.vaccine.2019.08.073

67. Coughtrie $A L$, Jefferies JM, Cleary D, Doncaster CP, Faust $S$, Kraaijeveld A, et al. Microbial epidemiology and carriage studies for the evaluation of vaccines. J Med Microbiol. 2019;68(10):1408-18. https://doi.org/10.1099/jmm. 0.001046 .

\section{Publisher's Note}

Springer Nature remains neutral with regard to jurisdictional claims in published maps and institutional affiliations.
Ready to submit your research? Choose BMC and benefit from:

- fast, convenient online submission

- thorough peer review by experienced researchers in your field

- rapid publication on acceptance

- support for research data, including large and complex data types

- gold Open Access which fosters wider collaboration and increased citations

- maximum visibility for your research: over $100 \mathrm{M}$ website views per year

At $\mathrm{BMC}$, research is always in progress.

Learn more biomedcentral.com/submissions 